\title{
TRIAGEM FITOQUÍMICA E ATIVIDADE ANTIBACTERIANA DOS EXTRATOS AQUOSO E HIDROALCOÓLICO BRUTOS DE Jacaranda micrantha Cham. ("CAROBA") SOBRE CEPAS DE Staphylococcus coagulase positiva E Salmonella spp. PADRÕES E ISOLADAS EM PRODUTOS DE ORIGEM ANIMAL
}

\author{
(Phytochemical screening and antibacterial activity of the crude aqueous and \\ hydroalcoholic extracts of Jacaranda micrantha Cham. ("caroba") on strains of \\ coagulase-positive Staphylococcus and Salmonella spp. standards and isolated in \\ products of animal origin)
}

Tainá Drebes ${ }^{1}$, Eduardo Miranda Ethur ${ }^{1}$, César Augusto Marchionatti Avancini ${ }^{*}$

\footnotetext{
1 Universidade do Vale do Taquari, Lageado, Rio Grande do Sul, Brasil

2 Universidade Federal do Rio Grande do Sul, Porto Alegre, Rio Grande do Sul, Brasil. *Corresponding author: cesar.avancini@ufrgs.br
}

RESUMO: A resistência microbiana a compostos químicos convencionais e demanda por tecnologias adequadas ao sistema de produção orgânico/agroecológico motivaram o desenvolvimento desta pesquisa na busca de soluções antibacterianas originadas de extrações vegetais. Os objetivos foram realizar uma triagem fitoquímica e avaliar a atividade biológica dos extratos aquoso (EA) e hidroalcoólico (EH) brutos de Jacaranda micrantha Cham. Com o teste de suspensão quantitativo os extratos das folhas nas concentrações de $50 \mathrm{mg} / \mathrm{mL}, 100$ $\mathrm{mg} / \mathrm{mL}$ e $200 \mathrm{mg} / \mathrm{mL}$ foram confrontados com as cepas Staphylococcus aureus ATCC 25923 e Salmonella Choleraesuis ATCC 10708, e na de $10 \mathrm{~g}: 100 \mathrm{~mL}$ (100 $\mathrm{mg} / \mathrm{mL}$ ) com isoladas em alimentos de origem animal: S. coagulase positiva $(\mathrm{N}=20)$ e Salmonella spp. ( $\mathrm{N}=20)$. As densidades populacionais de confronto (DP) foram 107, 106 e $105 \mathrm{UFC} / \mathrm{mL}$, nos tempos de contato de 8 e 24 horas. A análise fitoquímica qualitativa detectou a presença de compostos fenólicos, taninos condensados e flavonas tanto no EA quanto no $\mathrm{EH}$, e de saponinas apenas no EA. Foi praticamente inexistente a atividade antibacteriana do EA. Já o $\mathrm{EH}$, tomando como referência a proporção 10:100, nas $24 \mathrm{~h}$ de contato inativou as duas cepas padrões (exceção da Salmonella na maior DP). Frente as isoladas, apresentou melhor atividade sobre S. coagulase positiva reduzindo a DP ou inativando $70 \%$ delas na 107, 95\% na 106 e $100 \%$ na $105 \mathrm{UFC} / \mathrm{mL}$. As evidências mostram que além das variáveis proporção massa: volume, densidade populacional e tempo de confronto, características intrínsecas dos gêneros e dos indivíduos isolados interferiram na atividade dos extratos. Concluiu-se que o EA pouco apresentou atividade antibacteriana, e que o $\mathrm{EH}$ apresentou maior efeito microbiológico frente aos gêneros confrontados.

Palavras-chave: agroecologia; antibacteriano; antisséptico; desinfetante; fitoterápico

ABSTRACT: Microbial resistance to conventional chemical compounds, as well as the demand for technologies which are appropriate for the organic/agro-ecological production system, motivated this study, which sought antibacterial solutions originating from vegetable extracts. The objectives were to undertake phytochemical screening and assess the activity of the crude aqueous extract $(\mathrm{AE})$ and hydroalcoholic extract (HE) of Jacaranda micrantha Cham. Using the quantitative suspension test, the extracts from the leaves, in the proportions $5 \mathrm{~g}: 100 \mathrm{~mL}, 10 \mathrm{~g}$ : 
$100 \mathrm{~mL}$ and $20 \mathrm{~g}: 100 \mathrm{~mL}$ were tested against the strains Staphylococcus aureus ATCC 25923 and Salmonella choleraesuis ATCC 10708, and at $10 \mathrm{~g}: 100 \mathrm{~mL}(100$ $\mathrm{mg} / \mathrm{mL})$ with isolates in foods of animal origin: $\mathrm{S}$. coagulase-positive $(\mathrm{N}=20)$ and Salmonella spp. $(\mathrm{N}=20)$. The population densities (PD) confronted were 107, 106 and $105 \mathrm{CFU} / \mathrm{mL}$, at contact times of eight and 24 hours. Qualitative phytochemical analysis detected phenolic compounds, condensed tannins and flavones in the AE and $\mathrm{HE}$, and saponins in the AE alone. Antibacterial activity of $\mathrm{AE}$ was practically nonexistent. For HE, however, with the proportion $10: 100$ as a reference, at 24 hours of contact, it deactivated the two standard strains (apart from Salmonella at the greater PD). Regarding the isolates, it presented greater activity on coagulasepositive S., reducing PD or deactivating $70 \%$ of them at $107,95 \%$ at 106 and $100 \%$ at $105 \mathrm{CFU} / \mathrm{mL}$. The evidence shows that besides the variables proportion weight : volume, populational density and confrontation period, intrinsic characteristics of the genera and individual isolates had effects on the extracts' activity. Conclusion: AE had little antibacterial activity and HE had a greater microbiological effect.

Keywords: agroecology; antibacterial; antiseptic; disinfectant; plant extrats

\section{INTRODUÇÃO}

Os gêneros bacterianos Staphylococcus e Salmonella possuem distribuição mundial, apresentando importância no âmbito das doenças transmissíveis devido à frequência com que aparecem envolvidos como agentes causais de infecções nos animais. São consideradas

patógenos epidemiologicamente importantes, por causarem enfermidades comuns transmissíveis entre animais e seres humanos (Acha \& Szyfres, 1989), A transmissão pode ocorrer tanto por contato direto entre os animais ou entre animais e humanos, por contato com o ambiente contaminado e mesmo através do consumo de alimentos de origem animal, principalmente carnes, ovos e leite.

$\mathrm{Na}$ gestão sanitária das doenças infecto-transmissíveis é necessário que se adotem procedimentos sobre os agentes morbígenos, no corpo do animal, o que é feito através da antibioticoterapia, ou mesmo por antissepsia. Quando eles estão no ambiente, em vida livre, adotam-se procedimentos de higiene como a desinfecção e a descontaminação (Guardabassi et al., 2010; Brasil, 2010).
Limitações no uso dos antimicrobianos convencionais podem ocorrer devido à resistência, seja intrínseca ou adquirida, dos microorganismos (Maillard et al, 2012; WHO, 2012). Também, sistemas tecnológicos de criação animal referenciados nos modelos orgânico/agroecológico demandam insumos e recursos sanitários veterinários considerados sustentáveis, renováveis, para que sejam usados em substituição ou em complementaridade aos produtos convencionais (Brasil, 2011), o que motiva a busca de novos compostos antimicrobianos. Entre as alternativas para superar essas limitações tem sido proposta, entre outras, o uso de drogas vegetais e de fitoterápicos, sendo que a utilização de extratos brutos facilitaria o acesso de higienistas-sanitaristas ou de clínicos a esses recursos.

0 estudo da atividade antimicrobiana de vegetais vem se desenvolvendo como no trabalho apresentado por Avancini e Wiest (2008), que selecionaram 21 plantas nativas do sul do Brasil com indicativo etnográfico medicinal, com ênfase à. etnomedicina veterinária, etnosotaxia e etnoterapêutica de doenças de pele. A seleção das plantas ocorreu pela 
informação de serem usadas popularmente em doença de pele por serem "antibióticas". A triagem para verificação da atividade bioativa antimicrobiana das soluções aquosa e hidroalcóolica dos vegetais selecionados incluiu Jacaranda micrantha Cham., tendo sido demonstrada a ação sobre cepas padronizadas de Staphylococcus aureus e Salmonella choleraesuis, o que serviu de referência para a realização da investigação que se está apresentando.

Outros estudos etnográficos relataram atividades etnofamacológicas atribuídas a essa árvore como para "limpar o sangue" (Carvalho, 2004), e a casca e as folhas para "uso em feridas" (Fenner et al., 2006).

Sobre atividade antimicrobiana de J. micrantha, além do trabalho de Avancini e Wiest (op.cit.) encontrou-se apenas mais dois. Um quando extrato da planta foi confrontado também com micro-organismos padrões, mas nenhum frente isolados em situaçõesproblema sanitários ("de campo"). Silva e Bauer (1983), à partir do extrato clorofórmico das folhas isolaram um fitoquinol. O composto isolado foi testado pelo método de difusão em placa contra micro-organismos não tendo promovido inibição dos fungos Aspergillus niger ATCC 16404 e Candida albicans ATCC 10231, mas teve ação sobre as bactérias Staphylococcus aureus ATCC 6538 e S. aureus ATCC 25923. O extrato clorofórmio também foi testado com respeito a suas atividades antineoplásicas, obtendo-se resultados negativos.

Outro relato de atividade biológica foi apresentada por Santos et al. (1999), quando fracionaram o extrato da madeira e casca e, guiados pelo bioensaio de letalidade utilizando Artemia salina e pela atividade tripanocida, isolaram os constituintes bioativos identificados como jacaranona e uma mistura de estigmasterol e sitosterol.

A família botânica Bignoniaceae está distribuída mundialmente nas regiões tropicais, ocorrendo com grande frequência no continente sul-americano. É composta por 113 gêneros, entre os quais se encontra o Jacaranda (Carvalho et al., 2009). A Jacaranda micrantha Cham. é conhecida popularmente como "caroba", de ocorrência no Paraguai, Argentina e Brasil, onde encontra-se distribuído desde o estado de Minas Gerais até o Rio Grande do Sul (Sobral e Jarenkow, 2006). É uma árvore de grande porte, podendo ser empregada na construção civil, além de ser utilizada como planta medicinal e para regeneração de áreas degradadas com a finalidade de preservação permanente (Backes e Irgang, 2002).

Uma revisão sobre composição química e atividades bioativas do gênero Jacaranda podem ser vistas em Gachet e Schühly (2009). Os autores anotaram a descrição de 49 espécies e 8 subespécies com ocorrência na América do Sul, observaram que as espécies do gênero possuem grupos químicos em comum, mas nem sempre a mesma composição química, e que espécies diferentes promovem atividades biológicas também diferentes. $\mathrm{Na}$ publicação da revisão que realizaram, não foi informado nenhum trabalho científico sobre J. micrantha.

Os objetivos deste estudo foram realizar triagem fitoquímica dos extratos aquoso e hidroalcoólico brutos das folhas de J. micrantha a fim de verificar grupos químicos de metabólitos secundários presentes e avaliar a atividade antibacteriana dessas formas galênicas em diferentes proporções massa das folhas da planta : volume do solvente, frente cepas de Staphylococcus coagulase positiva e Salmonella spp. padrões e isoladas em produtos de origem animal. 


\section{MATERIAL E MÉTODOS}

\section{Amostra vegetal}

A amostra de Jacaranda micrantha Cham. foi um exemplar localizado no Campus do Centro Universitário Vale do Taquarí (Univates) município de

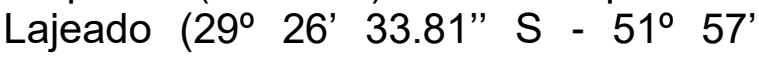
12.56" O), região Central do Rio Grande do Sul. A coleta foi realizada no mês de novembro de 2012, quando em floração. A planta foi identificada botanicamente, a partir de exsicata, pela Profa ${ }^{\text {. Elisete }}$ Freitas, do Departamento de Botânica do Centro Universitário Univates, sendo esta posteriormente encaminhada para registro e depósito junto ao Herbário do Instituto de Biociências/Departamento de Botânica da Universidade Federal do Rio Grande do Sul, Porto Alegre/RS/BR, recebendo o número de registro ICN 176815. Para todos os extratos foram utilizadas folhas secas a temperatura ambiente.

\section{Extratos}

Foi realizada uma triagem inicial com as proporções massa de folhas: volume de solvente $(\mathrm{m}: \mathrm{v})$ de $5 \mathrm{~g}: 100$ $\mathrm{mL}, 10 \mathrm{~g}: 100 \mathrm{~mL}$ e $20 \mathrm{~g}: 100 \mathrm{~mL}$. Essas proporções produziram extratos/soluções em concentrações que correspondem a $50 \mathrm{mg} / \mathrm{mL}, 100$ $\mathrm{mg} / \mathrm{mL}$ e $200 \mathrm{mg} / \mathrm{mL}$, respectivamente. No confronto com as bactérias isoladas, unicamente a segunda proporção foi usada.

$O$ extrato aquoso bruto (EA) foi preparado com água destilada estéril, levada à ebulição em fogo brando por 15 minutos, em frasco de Erlenmeyer (com boca parcialmente coberta), e posterior reconstituição do volume (evaporado) inicial também com água destilada estéril. Foi preparado sempre no mesmo dia em que eram realizados os testes.

O preparo do extrato hidroalcoólico bruto (EH) foi por maceração hidroalcoólica (tintura) com álcool etílico de cereais em $70^{\circ} \mathrm{GL}$. Após o período de 15 dias, o álcool foi retirado com aparelho evaporador rotativo (Marca Fisatom $\AA$, modelo $802 \quad$ D), a temperatura de $60^{\circ} \mathrm{C}$, sob pressão reduzida (Farmacopéia, 1959), com posterior reconstituição do volume inicial com água destilada estéril.

Para o controle de esterilidade dos extratos, uma alíquota de $0,1 \mathrm{~mL}$ de cada foi inoculada em placas contendo Ágar TSA (Tryptic Soy Agar, OXOID ${ }^{\circledR}$ ), sendo espalhado sobre a superfície com auxílio de uma alça de Drigalski e posteriormente incubado a $36^{\circ} \mathrm{C} \pm 1^{\circ} \mathrm{C}$, por 24 horas.

\section{Amostras bacterianas}

As cepas padrões para triagem foram Staphylococcus aureus ATCC 25923 e Salmonella Choleraesuis ATCC 10708.

A Organização Mundial de Saúde Animal, através do "Código de Saúde para Animais Terrestres" (OIE, 2012), informa que 0 monitoramento da atividade de antimicrobianos sobre bactérias de origem animal pode ser feita por coletas em diferentes etapas da cadeia de produção dos alimentos, incluindo o processamento de produtos de origem animal, em embalagens e pontos de venda. Dessa forma, assim como foi sugerido, coletaram-se as cepas em produtos de origem animal que estavam aguardando a liberação para a venda.

As cepas Staphylococcus coagulase positiva $(\mathrm{N}=20)$ e Salmonella spp. $(\mathrm{N}=20)$ foram isoladas em amostras de alimentos recebidas em Laboratório de Microbiologia de Alimentos, com Acreditação da ISO 17025:2005. Foram obtidas em diferentes tipos de produtos de origem

animal (cortes de carnes, linguiça, farinha de carne, queijo, ovos, etc.) e coletadas em dias diferentes assim 
como de empresas distintas para se evitar a seleção de possíveis clones.

Das cepas de Staphylococcus coagulase positiva $60 \%$ eram de produtos de origem avícola, $15 \%$ de origem suína, $15 \%$ de origem mista e $10 \%$ bovina. Das cepas isoladas de Salmonella spp, $40 \%$ eram de produtos de origem suína, $35 \%$ avícola, $15 \%$ bovina e $10 \%$ de origem mista.

Logo após o isolamento as cepas foram congeladas $\left(-20^{\circ} \mathrm{C}\right)$ em criotubos contendo caldo $\mathrm{BHI}$ (caldo de infusão cérebro e coração - OXOID $^{\circledR}$ ) e glicerol $\left(\right.$ Vetec $\left.^{\circledR}\right)$, na proporção $1: 1 \mathrm{~mL}$.

\section{Avaliação \\ da \\ Atividade \\ Antimicrobiana}

Foi usado o Teste de Suspensão Quantitativa para Avaliar Atividade Bactericida de Desinfetantes e Antissépticos Químicos, como descrito no protocolo do Comitê Europeu de Padronização (CEN) número EN 1040: 2005 (fase 1) (BSI, 2006; Chojecka et al., 2015), cuja modificação foi o confronto dos extratos com diferentes densidades populacionais bacterianas, e não com diferentes diluições geométrica dessas soluções como no protocolo original.

A reativação bacteriana foi realizada retirando $0,1 \mathrm{~mL}$ do caldo $\mathrm{BHI}$ contido no criotubo e adicionado a outro tubo contendo caldo $\mathrm{BHI}$ que foi incubado a $36 \pm 1{ }^{\circ} \mathrm{C}$ por $24 \mathrm{~h}$. Uma alíquota de $0,1 \mathrm{~mL}$ foi inoculada em superfície do ágar TSA sendo espalhado com auxílio de uma alça de Drigalski e posteriormente incubado a $36^{\circ} \mathrm{C} \pm 1^{\circ} \mathrm{C}$, por 24 horas.

A partir desta cultura foi realizada a padronização da densidade dos inóculos utilizando-se a escala padrão 0,5 de McFarland, resultando em aproximadamente $1,5 \times 10^{8} \mathrm{UFC} / \mathrm{mL}$ de micro-organismos. Nos testes foram utilizadas três densidades populacionais (DP) iniciais de confronto: $10^{7} \mathrm{UFC} / \mathrm{mL}$, $10^{6} \mathrm{UFC} / \mathrm{mL}$ e $10^{5} \mathrm{UFC} / \mathrm{mL}$. Os tempos de contato para leitura foram de 8 h e 24 h.

Depois de cada tempo de contato, dos tubos de ensaio contendo $1 \mathrm{~mL}$ da suspensão de bactérias e $9 \mathrm{~mL}$ das soluções extrato aquoso ou extrato hidroalcoólico $1 \mathrm{~mL}$ era retirado e colocado em tubo de ensaio com $9 \mathrm{~mL}$ de caldo $\mathrm{BHI}$ com solução neutralizadora ( $3 \%$ de polissorbato 80 , $0,3 \%$ de lecitina e $0,1 \%$ de histidina) onde permanecia por um período de cinco minutos. Para cada tempo de contato foi retirada uma alíquota de 0,1 $\mathrm{mL}$, em duplicata, e inoculada por espalhamento em superfície em placa de Petri com ágar TSA, incubando-se a $36^{\circ} \mathrm{C} \pm 1^{\circ} \mathrm{C}$, por 24 horas. Após o tempo de incubação procedeu-se a leitura das placas visando determinar 0 efeito microbiológico (EM). O EM (Reybrouck, 1998) é obtido quantificando o número de colônias crescidas e verificando se não houve redução ( $\mathrm{s} / \mathrm{r} \mathrm{log}$ ) ou se houve redução logarítmica (c/r log) ou mesmo eliminação bacteriana total (I inativação) em relação a densidade populacional inicial.

Ressalta-se que na contagem das colônias, para as placas que apresentaram crescimento maior que o intervalo de precisão do método (> 330 UFC), o resultado foi expresso como sem atividade (ou sem redução da densidade populacional - $s / r$ log). As leituras das placas que não apresentaram colônias foram consideradas como inativação total (I) do micro-organismo testado.

\section{Triagem fitoquímica}

A triagem fitoquímica foi realizada com adaptações a partir de Harborne (1998), Simões et al., (2002) e Farmacopeia Brasileira (1988). Para realização das técnicas de triagem, foram utilizados diretamente os extratos vegetais no modo de uso dos utilizados no teste de suspensão quantitativa. A escolha dos grupos fitoquímicos fez-se 
a partir de registros bibliográficos da família Bignoniaceae, principalmente de espécies do gênero Jacaranda. Foram selecionados para teste os compostos fenólicos, taninos, flavonoides, cumarinas, quinonas, saponinas e alcaloides.

\section{Compostos fenólicos}

Realizou-se a extração dos extratos vegetais, cerca de $20 \mathrm{~mL}$, em banho-maria fervente durante 30 minutos. Após resfriamento, filtrou-se e o conteúdo foi dividido em 3 tubos de ensaio ( $A, B$ e $C$ ). No tubo $A$, foram adicionadas de 3 a 5 gotas de uma solução aquosa de cloreto férrico $1 \%$. 0 desenvolvimento de coloração verde ou azul escura é indicativo da presença de compostos fenólicos. No tubo B, foram adicionadas de 3 a 5 gotas de solução aquosa de hidróxido de potássio $3 \%$. 0 aparecimento ou intensificação da cor amarela ou laranja é indicativo da presença destes compostos. O tubo C foi utilizado como controle para verificação da coloração inicial do extrato.

\section{Taninos}

O processo de extração foi realizado como dos compostos fenólicos e divididos em tubos. Preparou-se uma solução aquosa de gelatina $1 \%$. Aos tubos denominados $A$, já contendo os extratos, foram adicionados $1 \mathrm{~mL}$ da solução aquosa de gelatina. $\mathrm{Na}$ presença de taninos ocorre a formação de turvação ou precipitado.

Para a técnica de caracterização, primeiramente foi preparada uma solução aquosa de cloreto férrico $1 \%$, após foram adicionadas três gotas desta solução aos tubos denominados B, contendo os extratos. $\mathrm{Na}$ presença de taninos hidrolisáveis ocorre o desenvolvimento de coloração azulada e na presença de taninos condensados a coloração verde.
O tubo C foi utilizado como controle para verificação da coloração inicial do extrato.

\section{Flavonóides}

Após extração em banho-maria fervente por 30 minutos, foi aguardado o resfriamento do extrato e realizada a filtração em papel filtro e posteriormente realizada a extração, duas vezes, em funil de separação utilizando $10 \mathrm{~mL}$ de n-butanol. A evaporação da fração butanólica foi realizada à secura em cápsula de porcelana, e retomado o extrato em metanol (cerca de $10 \mathrm{~mL}$ ). Foi realizada então a transferência para 2 tubos de ensaio ( $A$ e $B$ ). No tubo $A$ foi adicionado $0,5 \mathrm{~mL}$ de ácido clorídrico concentrado e após $0,1 \mathrm{~g}$ de magnésio metálico. $O$ desenvolvimento da coloração laranja indica a presença de flavonas, a coloração violácea indica flavanonas e a cor vermelha a presença de flavonóis. $O$ tubo $B$ foi utilizado como controle para a verificação da coloração inicial do extrato.

\section{Cumarinas}

Para verificação de cumarinas, foi realizado o aquecimento em tubo de ensaio, de cerca de $10 \mathrm{~mL}$ dos extratos em banho-maria fervente. O tubo foi tampado com papel filtro previamente impregnado e seco com uma solução metanólica de hidróxido de potássio $5 \%$. Após 10 minutos os papéis foram expostos à luz ultravioleta (UV) de 365 $\mathrm{nm}$. O desenvolvimento da fluorescência azul e amarela indica a presença de cumarinas voláteis.

\section{Quinonas}

Para o teste de quinonas extraiuse em banho-maria fervente durante 10 minutos, $10 \mathrm{~mL}$ dos extratos vegetais com $5 \mathrm{~mL}$ de hidróxido de potássio $5 \%$. seguida foi realizada a extração com 5 $\mathrm{mL}$ de tolueno em funil de separação. Separou-se em um béquer a fase orgânica e adicionou-se $2 \mathrm{~mL}$ de 
solução de hidróxido de potássio $3 \%$. 0 desenvolvimento de coloração vermelha indica a presença de antraquinonas, a coloração violácea indica a presença de naftoquinóides e o surgimento de coloração azul indica a presença de benzoquinóides.

Já para verificar a presença de quinonas glicosídicas, ferveu-se em banho-maria cerca de $10 \mathrm{~mL}$ dos extratos vegetais com $10 \mathrm{~mL}$ de ácido clorídrico $10 \%$ durante 15 minutos. Após resfriamento, filtrou-se e adicionou-se 5 $\mathrm{mL}$ de tolueno ao extrato. Separaram-se as fases, e na fase orgânica foi adicionado $2 \mathrm{~mL}$ do reagente de Bornträger. $O$ aparecimento da coloração vermelha na fase aquosa indica a presença de quinonas glicosídicas.

\section{Saponinas}

Extraiu-se cerca de $10 \mathrm{~mL}$ de extratos vegetais em banho-maria fervente por 15 minutos. Após o resfriamento, filtrou-se e colocou-se em um tudo de ensaio. O tubo foi agitado vigorosamente durante 15 segundos, e a altura da coluna de espuma formada, foi medida com o auxílio de uma régua. $O$ desenvolvimento de espuma com altura superior a $1 \mathrm{~cm}$ e persistência da mesma após repouso de 15 minutos e adição de ácido clorídrico 10\% indica a presença de saponinas.

\section{Alcalóides}

Foram diluídos aproximadamente $10 \mathrm{~mL}$ dos extratos vegetais em $20 \mathrm{~mL}$ de metanol. Após, esta solução foi dividida igualmente em 3 tubos de ensaio. Na sequência foram adicionados em cada tubo, $5 \mathrm{~mL}$ de ácido clorídrico $10 \%$. Os mesmos foram aquecidos em banho-maria $\left(40^{\circ} \mathrm{C}\right)$ durante 30 minutos. Após o resfriamento, filtrou-se e transferiu-se uma parte deste para um vidro de relógio, onde foram adicionados gota a gota os seguintes reagentes de detecção: Mayer, Dragendorff e
Wagner. $O$ aparecimento de um precipitado indica a presença de alcalóides.

\section{RESULTADOS E DISCUSSÃO}

Os resultados do confronto dos extratos com as cepas padrões encontram-se nas Tabelas 1 e 2 Podese observar que 0 extrato aquoso exerceu praticamente nenhum efeito microbiológico seja sobre $S$. aureus ATCC 25923 ou sobre $S$. Choleraesuis ATCC 10708, no máximo promovendo pequena redução logarítmica, independente da proporção $\mathrm{m}: \mathrm{v}$, densidade populacional de confronto e tempo de contato. Já o extrato hidroalcoólico agiu sobre as duas cepas padrões seja reduzindo a densidade populacional ou inativando essas bactérias em todas as proporções testadas, tendo-se que quanto menor a densidade populacional e maior tempo de contato, maior a atividade.

Tabela 1 - Atividade antibacteriana (Efeito Microbiológico) do extrato aquoso bruto (EA) e do extrato hidroalcoólico bruto $(\mathrm{EH})$ das folhas de Jacaranda micrantha Cham. (caroba), em diferentes tempos de contato e proporções planta : volume, sobre densidades populacionais da cepa padrão Staphylococcus aureus ATCC 25923.

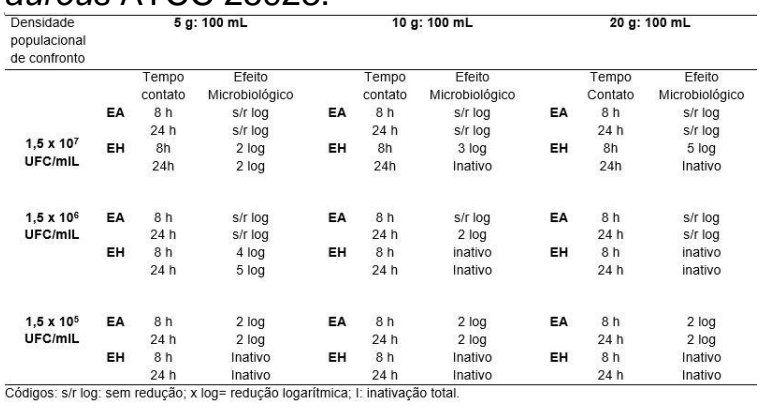

Os dados do confronto do extrato aquoso (proporção 10: 100) frente as cepas isoladas em alimentos de origem animal não estão em tabelas, e serão apresentados à seguir. Os resultados evidenciaram que o extrato aquoso, em todas as proporções, pouco promoveu redução das densidades populacionais 
agindo de modo semelhante ao confronto com as duas cepas padrão. Frente estafilococos mesmo na menor densidade populacional, de $10^{5}$ UFC/mL, no tempo de contato de $8 \mathrm{~h}$, em $75 \%$ das cepas não promoveu redução logarítmica e em $25 \% 2$ log, e em 24 h $20 \%$ não apresentaram redução, 55\% reduziram 1 log, 15\% reduziram 2 log e 10\% reduziram 3 log. Frente as salmonelas, na mesma densidade populacional e no tempo de contato de $8 \mathrm{~h}, 90 \%$ das cepas reduziram 1 log e 10\% 2 log, e no tempo de 24 h 55\% das amostras não tiveram redução, 40\% reduziram 1 log e 5\% reduziram 2 log.

Tabela 2 - Atividade antibacteriana (Efeito Microbiológico) do extrato aquoso bruto (EA) e do extrato hidroalcoólico bruto $(\mathrm{EH})$ das folhas de Jacaranda micrantha Cham. (caroba), em diferentes tempos de contat o e proporções planta:volume, sobre densidades populacionais da cepa padrão Salmonella Choleraesuis ATCC10708.

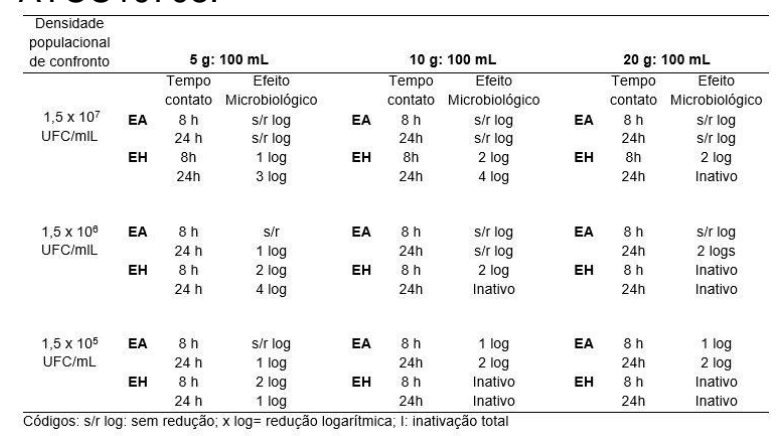

A atividade do extrato hidroalcoólico (10:100) frente as cepas isoladas pode ser verificado na Tabela 3 , onde observa-se semelhança quando do confronto com as cepas padrões: quanto menor a densidade inicial da população bacteriana e quanto maior o tempo de contato, maior o número de cepas com redução logarítmica ou inativadas. O maior percentual de cepas com redução logarítimica e inativadas foi promovido frente à Staphylococcus coagulase positiva.

Mas também se observa, lendo a Tabela 3, que nem todas as cepas isoladas sofrem ação bactericida dos extratos, de redução logarítmica ou de inativação como ocorreu com as cepas padrões, exigindo esse fenômeno melhor estudo para tentar explicar quais fatores relacionados às unidades experimentais podem ter determinado esse resultado. Aliás, esse resultado alerta para o necessário cuidado quando na escolha de insumos sanitários, sejam convencionais ou de extração vegetal, posto que o registro de produtos antimicrobianos é feito baseado em confronto com cepas padrões o que exige, baseando-se nos resultados obtidos, para cada situaçãoproblema sanitário o monitoramento da susceptibilidade e sensibilidade da amostra presente.

Tabela 3 - Número de isolados de Staphylococcus coagulase positiva $(\mathrm{N}=20)$ e Salmonella spp. ( $\mathrm{N}=20)$ que sofreram redução logarítmica ou inativação total (Efeito Microbiológico), em diferentes densidades populacionais microbianas e diferentes tempos de contato, quando confrontados com o extrato hidroalcoólico bruto (EH) das folhas de Jacaranda micrantha Cham, na proporção de $10 \mathrm{~g}: 100 \mathrm{~mL}$

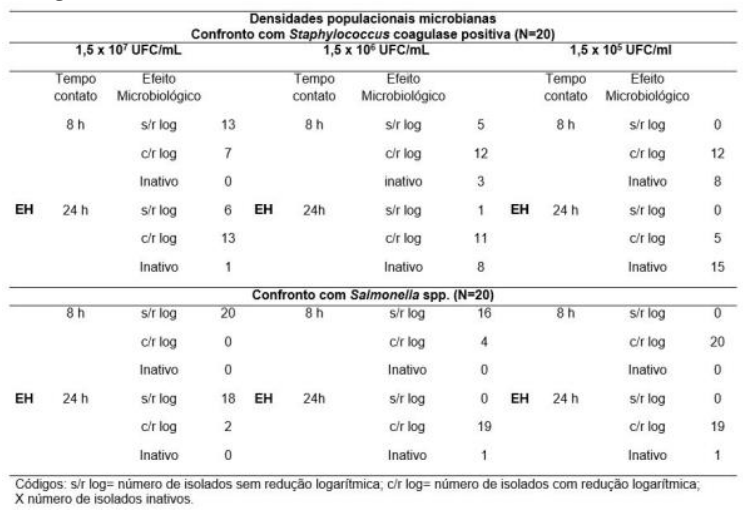

Comparando, de modo descritivo, a atividade do extrato hidroalcoólico sobre as cepas isoladas Staphylococcus coagulase positiva com a exercida sobre a padrão, em $10^{7} \mathrm{UFC} / \mathrm{mL}$, nas $8 \mathrm{~h}$ de contato, $65 \%$ das isoladas não sofreram redução logarítmica, ao passo $35 \%$ delas sofreram redução semelhante ao ocorrido com a padrão; nas $24 \mathrm{~h}$ apenas uma $(5 \%)$ sofreu inativação, como ocorreu com a padrão, 65\% apresentou 
redução logarítmica entre 3-5 log e 30\% sofreu nenhuma atividade. $\mathrm{Em} 10^{6}$ UFC/mL, na leitura das 8 h $15 \%$ das isoladas estavam inativadas como a padrão, mas $60 \%$ sofreram redução logarítmica e $25 \%$ não sofreram atividade; nas 24 h, 40\% estavam inativadas como a padrão, $55 \%$ apresentaram redução logarítmica e apenas uma não sofreu atividade. Em $10^{5} \mathrm{UFC} / \mathrm{mL}$, nas $8 \mathrm{~h} 40 \%$ e em $24 \mathrm{~h}$ $75 \%$ estavam inativadas como a padrão, sendo que nesta densidade todas as cepas sofreram redução logarítmica.

Fazendo a mesma comparação com a Salmonella spp. em $10^{7} \mathrm{UFC} / \mathrm{mL}$, nas $8 \mathrm{~h}$ de contato enquanto a padrão havia redução logarítmica de 2 log $100 \%$ das isoladas sofreu nenhuma ação; nas $24 \mathrm{~h}$, enquanto a padrão reduziu $4 \log$, apenas $20 \%$ das isoladas sofreu essa atividade e $80 \%$ não sofreu a ação. Em $10^{6} \mathrm{UFC} / \mathrm{mL}$, nas $8 \mathrm{~h}$ de contato, apenas $20 \%$ das isoladas apresentou redução logarítmica de 2 log como a padrão; nas $24 \mathrm{~h}$ apenas $5 \%$ (uma) estava inativada como a padrão, e $95 \%$ delas apresentaram redução logarítmica de 2-3 log. Em $10^{5} \mathrm{UFC} / \mathrm{mL}$, nas $8 \mathrm{~h}$, nenhuma inativada, o que havia acontecido com a padrão, apesar de todas terem sofrido redução logarítmica, e nas $24 \mathrm{~h}$ apenas 5\% (uma) estava inativada como a padrão e as restantes $95 \%$ delas apresentou redução logarítmica de 2-3 log.

Para obter resultados confiáveis sobre a ação bactericida dos extratos testados foi utilizado, como descrito no protocolo do teste, uma solução neutralizadora. Os neutralizantes são frequentemente usados em testes de desinfetantes convencionais e têm como função inativar resíduos da substância antimicrobiana, após a exposição do inóculo (Reybrouck, 1998). Este procedimento tem a finalidade de evitar observações "falso-negativas", expressas pela possível ação somente de inibição microbiana, confundindo com a ação de inativação. Como não são padronizados neutralizadores específicos para extrações vegetais, foram mantidos os indicados no protocolo europeu do teste, que correspondem aos mesmos utilizados com resultados adequados em outros estudos (Mota et al., 2011; Sperotto et al., 2012) com extrações vegetais. Desse modo, pretendeu-se assegurar que 0 extrato promoveu ação bactericida, e não bacteriostática, sobre os inóculos.

Para comparação dos resultados da atividade antibacteriana com os de outros autores, como informado na secção introdução, foram encontradas dois trabalhos. Avancini e Wiest (2008), que com teste de suspensão e proporção planta $10 \mathrm{~g}$ : volume $100 \mathrm{~mL}$, apesar de protocolo diferente do aqui utilizado, também observaram maior atividade (leitura apenas nas $24 \mathrm{~h}$ de contato) do extrato hidroalcoólico do que - aquoso. O que diferencia dos resultados aqui obtidos é que apesar do extrato hidroalcoólico promover as ações de inibição e inativação tanto sobre o $S$. aureus quanto $S$. Cholaerasuis padrões, maior atividade foi sobre a bactéria Gram-negativa. Maior diferença foi quanto ao extrato aquoso, que não apresentou atividade frente Staphylococcus mas sim frente Salmonella. Para explicar esse fato, pode-se assumir que algumas diferenças de atividade biológica possam ocorrem em plantas do mesmo gênero e espécie porque os metabólitos secundários podem sofrer variações devido condições temporais, como sazonalidade e mesmo diário, periodo de coleta, características climáticas e ambiente geográfico, como apontado por Darrow e Bowers (1997).

A atividade sobre Staphylococcus aureus, mesmo que usando outro método e solvente, também foi observada por Silva e Bauer (1983). 
A intenção de utilizar diferentes densidades populacionais iniciais referese ao fato de poder simular o que concretamente ocorre em diferentes ambientes, seja sobre tecidos vivos ou superfícies inanimadas, quando estão colonizadas por diferentes quantidades de micro-organismos. E observou-se que esses diferentes cenários sanitários também interfiram na atividade dos extratos. À semelhança dos resultados do confronto dos extratos com a cepa padrão e as isoladas, foi recorrente a relação entre densidade populacional inicial e tempo de contato para obter-se efeito microbiológico/atividade antibacteriana. Quanto maior a densidade populacional inicial, maior o tempo de contato necessário para a redução logarítmica ou inativação das cepas. Sobre esse fenômeno, qual seja a relação da densidade populacional e a curva de morte microbiana por tempo de contato já foi descrito e pode ser visto, por exemplo, em Tortora et al. (2012).

Observou-se, já no teste com as cepas de referência (Tabelas 1 e 2), que a proporção folhas da planta: proporção e tipo do solvente interfere na eficiência da intensidade da atividade dos extratos frente às diferentes densidades populacionais. A utilização da proporção de confronto dos extratos em $10 \mathrm{~g}: 100$ $\mathrm{mL}$ com as cepas isoladas foi motivado pela necessidade de testar os extratos com a menor massa vegetal, tendo como referência a eficiência apresentada frente as cepas padrões. Fica como hipótese que se confrontadas as cepas isoladas em proporção maior de folhas, a eficácia da ação de redução logarítmica ou inativação sobre os isolados deverá igualmente ser maior.

A análise fitoquímica detectou a presença de compostos fenólicos, taninos condensados e flavonas tanto no extrato aquoso quanto no hidroacoólico. Saponinas também foram detectadas, mas apenas no extrato aquoso. Este resultado coincide com estudos fitoquímicos (Munoz-Mingarro et al., 2003; Gachet e Schühly, 2009; Arruda et al., 2012) de algumas espécies da família Bignoniaceae que demonstraram a presença de diversas classes de substâncias químicas, entre elas, compostos fenólicos, taninos e flavonoides. No entanto, cumarinas, quinonas e alcalóides, igualmente citados como frequentes, não foram detectados tanto nos extratos aquoso quanto no hidroalcoólico.

Pilatti (2012) também realizou estudo fitoquímico utilizando o extrato bruto metanólico das folhas de $J$. micrantha, tendo igualmente identificado compostos fenólicos (taninos condensados). $O$ que difere dos resultados obtidos é que Pilatti (op.cit.) encontrou substâncias do grupo dos terpenos (saponinas) e alcaloides, porém, no extrato metanólico.

A presença de taninos condensados poderia explicar a atividade biológica das soluções de $J$. micrantha, pois segundo Simões et al. (2002), apresentam atividade bactericida e fungicida. Além disso, a presença de flavonóides, que conforme Pelzer et al. (1998), apresentam grandes efeitos sobre o sistema biológico, podendo-se citar a atividade antimicrobiana.

As diferentes intensidades na atividade biológica investigada entre os extratos hidroalcoólico e 0 aquoso poderia ser explicada pelas substâncias que compõem cada extrato, uma vez que os testes fitoquímicos são qualitativos indicando apenas a presença ou ausência de determinado grupo, mas não responde sobre qual (is) substância (s) está (ão) presente (s). Desta forma, a diferença de polaridade entre 0 extrato hidroalcoólico e o aquoso, além da temperatura durante 0 processo, poderia extrair diferentes substância dentro de um mesmo grupo, e a partir daí teríamos diferentes atividades biológicas. 
Isso explicaria porque as duas formas apresentaram atividade antibacteriana, porém 0 extrato hidroalcoólico apresentou maior capacidade de redução logarítmica ou de inativação frente às cepas padrões $e$ as isoladas quando comparado com 0 aquoso.

O estudo permitiu observar que o extrato hidroalcoólico bruto apresenta potencial para uso de modo direto sobre as fontes de infecção, sobre os gêneros de agentes causais confrontados, seja no ambiente inanimado em procedimentos de desinfecção ou de descontaminação ou ainda para ser utilizado sobre tecidos vivos como antisséptico e inclusive em formulações que the sirvam de veículo, como seria o caso de antibióticos.

\section{CONCLUSÕES}

Os resultados obtidos permitiram confirmar que os extratos das folhas de Jacaranda micrantha Cham. ("caroba") promovem atividade antibacteriana, possivelmente devido à presença de compostos fenólicos detectados nos extratos. As evidências mostram que além da proporção planta: volume, tipo de solvente, densidade populacional de confronto, tempo de contato, características intrínsecas dos gêneros Staphylococcus coagulase positiva e Salmonella spp. e dos indivíduos isolados influenciaram na atividade.

As evidências observadas da atividade do extrato hidroetanólico bruto, seja pela redução da carga ou pela inativação bacteriana, indicam seu potencial uso de modo direto sobre as fontes de infecção no ambiente (como desinfetante), ou no tecido animal (como antisséptico) ou mesmo em formulações que lhe sirvam como veículo (como em pomadas, ou após testes de farmacodinâmica, como antibiótico).

\section{REFERÊNCIAS}

ACHA, P.N.; SZYFRES, B. Zoonosis y enfermedades transmissibles comunes al hombre y a los animales. 2a. ed. Washington, D.C.: Organizacion Mundial de la Salud/Organizacion Panamericana de la Salud. Publicación Cientifica No. 503, 1989. 989 p.

ARRUDA, A.L.A.; SOUZA, D.G.; VIEIRA, C.J.B. et al. Análise fitoquímica e atividade antimicobacteriana de extratos metanólicos de Jacaranda cuspidifolia Mart. (Bignoniaceae). Revista brasileira de plantas medicinais. v. 14 , n. 2 , p. 276-281, 2012.

AVANCINI, C.A.M.; WIEST, J.M. Etnomedicina veterinária, etnonosotaxia e etnoterapêutica de doenças de pele como referência para seleção e avaliação preliminar da atividade antibacteriana de plantas nativas no sul do Brasil. Revista Brasileira de Plantas Medicinais, v. 10, n. 1, p. 2128, 2008.

BACKES, P.; IRGANG, B. Árvores do Sul. Guia de identificação e interesse ecológico: as principais espécies nativas sul-brasileiras. 1.ed. Santa Cruz do Sul: Editora Clube da Árvore/Instituto Souza Cruz, 2002. 325 p.

BRASIL, MINSTÉRIO DA AGRICULTURA, PECUÁRIA E ABASTECIMENTO (MAPA). Instrução Normativa no 46, de 6 de outubro de 2011. Regulamento Técnico para os Sistemas Orgânicos de Produção Animal e Vegetal. Diário Oficial da União, 7 de outubro de 2011.

BRASIL. AGÊNCIA NACIONAL DE VIGILÂNCIA SANITÁRIA. Segurança do paciente em serviços de saúde: limpeza e desinfecção de superfícies/Agência 
Nacional de Vigilância Sanitária. Brasília: Anvisa, 2010.116 p

\section{BRITISH STANDARDS INSTITUTION} (BSI). European Standard EN 1040:2005. Chemical disinfectants and antiseptics - quantitative - suspencion test for the evaluation of basic bactericidal activity of chemical desinfectants and antiseptics: test method and requerements (phase 1). Brussels: European Committee for Standardization, 2006.

CARVALHO, A.R. Popular use, chemical composition and trade of cerrado's medicinal plants (Goias, Brazil). Environment, Development and Sustainability, v. 6, p 307-316, 2004.

CARVALHO, C.; MATTA, S.; MELO, F. et al. Cipó-cravo (Tynnanthus fasciculatus Miers-Bignoniaceae): Estudo fitoquímico e toxicológico envolvendo Artemia salina. Revista Eletrônica de Farmácia, v. VI, n. 1, p. 51-57, 2009.

CHOJECKA, A.; WIERCIŃSKA, O.; RÖHM-RODOWALD, E. et al. Glucoprotamin antimicrobial activity against selected standard antibioticresistant bacteria and reference strains used in the assessment of disinfection efficacy. Rocz Panstw Zakl Hig. v. 66, n.3, 281-288, 2015.

DARROW, K.; BOWERS, M. D.. Phenological and Population Variation in Iridoid Glycosides of Plantago lanceolata (Plantaginaceae). Biochemical Systematics and Ecology, v. 25, n.1, p. 1-11,1997.

FARMACOPÉIA dos Estados Unidos do Brasil. 2.ed. São Paulo: Siqueira S.A., 1959.
FARCACOPEIA BRASILEIRA. 4.ed. Atheneu Editora São Paulo Ltda. São Paulo, 1988.

FENNER, R.; BETTI, H.H.; MENTZ, L.A. et al. Plantas utilizadas na medicina popular brasileira com potencial atividade antifúngica. Revista Brasileira de Ciências Farmacêuticas/Brazilian Journal of Pharmaceutical Sciences, v. 42, n. 3, p. 369-394, 2006.

GACHET, M.S.; SCHÜHLY, W. Jacaranda - An ethnopharmacological and phytochemical review. Journal of Ethnopharmacology. v. 121, p. 14-27, 2009.

GUARDABASSI, L.; JENSEN, L. B.; KRUSE, H. Guia de antimicrobianos em veterinária. Porto Alegre: Artmed, 2010. $268 p$

HARBORNE, J.B. Phytochemical methods: a guide to modern techiques of plant analysis. 3 edh. Springer Netherlands, 1998. 302 p.

MAILLARD,J.Y.;MCDONNELL,G.MAILL $A R D, J . Y$. et al. Selection and use of disinfectants. In Practice, v.34, n.4, p.292- 299,2012.

MOTA, F.M.; CARVALHO H.H.C.; WIEST J.M. Atividade antibacteriana in vitro de inflorescências de Achyrocline satureioides (Lam.) DC. - Asteraceae ("macela", "marcela") sobre agentes bacterianos de interesse em alimentos. Revista Brasileira de Plantas Medicinais, v. 13 , ก. 3 , p. 298-304, 2011.

MUNOZ-MINGARRO, D.; ACERO, N.; LINHARES, F. et al. Biological activity of extracts from Catalpa bignonioides Walt. (Bignoniaceaea). Journal of Ethopharmacology, v. 87, n. 2, p. 163167, 2003. 
ORGANIZACION MUNDIAL DE SANIDAD ANIMAL (OIE). Código sanitário para los animales terrestres.

Disponível em:

<http://www.oie.int/es/normas-

internacionales/codigo-terrestre/>.

Acesso em 11/nov/2014.

PELZER, L.; GUARDIA, T.; JUAREZ, A. et al. Acute and chronic antiinflammatory effects of plant flavonoids. IL Farmaco, v. 53, p. 421-424, 1998.

PILATTI, D.M. Ecofisiologia química de espécies nativas de dois biomas do estado do Paraná: perfil químico de espécies nativas recomendadas para restauração vegetal, proveniente de duas formações florestais no Estado do Paraná. 2012. 112p. Dissertação (Mestrado em Conservação e Manejo de Recursos Naturais) - Centro de Ciências Biológicas e da Saúde, Universidade Estadual do Oeste do Paraná, Cascavel.

REYBROUCK, G. The testing of disinfectants. International Biodeterioration \& Biodegradation, v. 41, p. $269-272,1998$.

SANTOS, C.A.; RASLAN, D.S.; CHIARI, E. et al. Bioguided assay of Jacaranda micrantha Cham. (BIGNONIACEAE). Acta Horticulture, n. 501: II WOCMAP Congress Medicinal and Aromatic Plants, Part 2: Pharmacognosy, Pharmacology, Phytomedicine, Toxicology,p..151-154, 1999.

SILVA, M.C.M.; BAUER L. Jacaranda micrantha cham. Isolamento e identificação de 1-hidróxi-4-oxo-2,5ciclohexadien-1-1cetato de etila, ensaios antineoplásicos, antibacterianos e antifúngicos. Ciência e Natura, n. 5, p.7-18, 1983.

SIMÕES, C.M.O.; SCHENKEL, E.P.; GOSMANN, G. et al. Farmacognosia da planta ao medicamento. 4. ed. Porto Alegre/Florianópolis : Ed. Universidade/UFRGS - Ed. da UFSC, 2002.

SOBRAL, M.; JARENKOW, J.A.; BRACK, P. et al. Flora arbórea e arborescente e do Rio Grande do Sul, Brasil. São Carlos, SP: Rima, 2006. 350 p.

SPEROTTO, V.R.; MURARI, A.L.; REBELLATTO, D.A. et al. Atividade do decocto de Achyrocline satureioides D.C. (Lam.) - Asteraceae ("macela") sobre bactérias padrões e isoladas em mastite bovina. Acta Scientiae Veterinariae, v. 40, n. 3, p. 1-7, 2012.

TORTORA, G. J.; FUNCKE, B. R.; CASE, C. L. Microbiologia. 10 ed. Porto Alegre : Artmed, 2012. 964 p.

WORLD HEALTH ORGANIZATION (WHO). The evolving threat of antimicrobial resistance: options for action. Geneva, Switzerland, 2012. Disponível em: < http://apps.who.int/iris/bitstream/10665/4 4812/1/9789241503181_eng.pdf>. Acessado em: 30 jun. $2 \overline{0} 17$. 